\title{
On the Application of Magnetoacoustic Emission for a Nondestructive Assessment of the Post Welding Heat Treatment of High Chromium Steel Weld Seams
}

\author{
L. Piotrowski ${ }^{1}$ (D. M. Chmielewski ${ }^{1} \cdot$ G. Golański ${ }^{2} \cdot$ K. Wojsyk ${ }^{3}$
}

Received: 14 December 2020 / Accepted: 13 April 2021 / Published online: 27 April 2021

(c) The Author(s) 2021

\begin{abstract}
The paper analyses the possibility of post weld heat treatment (PWHT) quality assessment with the help of magnetoacoustic emission (MAE) signal measurements. Two welded superheater tubes, made of high chromium VM12 steel, were analysed-as welded and heat treated one. The analysed sample in the as welded state exhibited significantly higher hardness, accompanied by a big difference in the MAE signal intensity (of order of about 50\%). In order to explain that, the influence of tempering on the MAE signal intensity is demonstrated for the very similar X20CrMoV12.1 steel. It is shown that the observed increase of the MAE intensity as a function of annealing time is directly correlated with the change in hardness. The as described dependence allows to propose a method based on the MAE signal measurements as a new tool for the PWHT assessment.
\end{abstract}

Keywords Welding $\cdot$ Post weld heat treatment $\cdot$ Nondestructive evaluation $\cdot$ Magnetoacoustic emission

\section{Introduction}

High chromium ( $12 \mathrm{wt} \%)$ tempered martensitic steels, such as VM12 or X20CrMoV12.1 are widely used in modern power plants. They combine two very useful properties-high creep resistance (resulting from precipitate distribution) and relatively high corrosion resistance (the result of high chromium content). Unfortunately, as-quenched martensitic phase is very brittle, so in order to obtain components combining optimum mechanical properties with creep resistance martensitic steels must be tempered before their implementation as industrial components. The process is well established and performed during manufacturing in a controlled way.

\section{Piotrowski}

lespiotr@pg.edu.pl

1 Faculty of Applied Physics and Mathematics, Gdansk University of Technology, 80-233 Gdańsk, Poland

2 Department of Material Engineering, Czestochowa Technical University, 42-200 Czestochowa, Poland

3 Department of Management and Production Engineering, Czestochowa Technical University, 42-200 Czestochowa, Poland
However similar problems (brittleness, cracking) may be a result of welding procedure performed during boiler assembly or repair in a power plant. In such a case the process is more vulnerable to human factor related errors. For high chromium steels all weldments have to undergo post weld heat treatment (PWHT) at a typical temperature in the range of $760-860{ }^{\circ} \mathrm{C}$ (depending on composition) for the purpose of stress relieving and in order to obtain optimal mechanical properties [1, 2]. Improper PWHT (e.g. heating method not adequate to the thickness of the component) may result in failure due to stress relieving [3]. In high chromium steels crack occurrence is strongly promoted by the retained non-tempered martensite [4]. In industrial practice, the most common method of PWHT quality assessment is based on hardness measurements. It has however two disadvantages. Firstly it requires that the weldment face is locally grinded flat in order to obtain even surface. Secondly the answer is obtained only from the external part of the investigated tube. Such information may not be satisfactory, especially in the case of multipass welding. Being so, a nondestructive method of weld properties assessment, capable of material interior investigation would be very helpful. There are some attempts being made to propose an industrially applicable solution of the abovementioned issue, to mention only such as e.g. 
[5] or application of ultrasonic measurements [6]. Very important part of the whole spectrum of possible methods are the ones based on magnetic methods, which have been shown to give reliable results in the case of spot welding quality assessment. One could apply such techniques as for instance the magnetic flux leakage test (MFL) [7], eddy currents [8], or a combined technique [9], using both for more accurate testing. It is also possible to apply an advanced method of magnetic hysteresis measurements based on the measurements of a whole family of minor hysteresis loops (magnetic adaptive testing) [10]. However spot welding is somewhat specific case, from the point of view of weld seam geometry which is a regular one. In case of welded pipes the face of the seam is irregular and MFL based techniques are inapplicable without prior polishing. As for the eddy current methods, they penetration depth, even though changeable with the help of magnetizing frequency adjustment, is not high enough to get to inner part of the pipe several millimetres thick. And, differently than in case of spot welding, there is no way to investigate the inner side of the pipe. From our experience we do believe that one of the applicable methods may be based on the magnetoacoustic emission (MAE) signal measurement. The MAE phenomenon was for the first time investigated in a systematic way by Lord [11] in 1975 and then in 1981 proposed by Shibata and Ono [12] as a nondestructive tool of stress measurement. It has already been shown that the MAE signal in martensitic steels is strongly dependent on the dislocation density, the change of which can be caused either by tempering process [13] or plastic deformation [14]. The MAE is a phenomenon of acoustic pulse generation during an irreversible jump of a domain wall (DW) inside the material with non-zero magnetostriction. Discontinuity of motion of DWs is a result of their interaction with pinning sites such as precipitates (of the size at least close to DW width, i.e. $\sim 50-100 \mathrm{~nm}$ ) or dislocation tangles. In ferrous materials we can discern two types of DWs $-90^{\circ}$ and $180^{\circ}$, where the angle describes the angle between magnetisation directions in neighbouring domains. The movement of only those of the first kind results in acoustic pulse generation, since the magnetostriction phenomenon, responsible for material elongation and hence the local change of volume during the DW jump, is an even effect-i.e. two antiparallel domains are equally elongated [15]. One of the advantages of the method based on the MAE signal measurements is that acoustic pulses (of ultrasound frequency) are weakly attenuated in steels, hence we can obtain information from the inside of the material, provided that we are able to magnetise it. There is no need of complicated surface preparation and use of expensive consumables. In addition to that the MAE noise signal is composed of relatively high frequency components and can be successfully separated from the background noise which is always present in industrial environment [16]. To our best knowledge the MAE signal measurements have never been proposed as a means of PWHT procedure quality assessment.

\section{Material and Methods}

\subsection{Investigated Material}

The material used for the assessment of welding quality consisted of cut outs from two superheater tubes made of VM12 steel. Before welding each of the tubes was cut in half (perpendicularly to its axis), both halves of the tubes were welded together and the obtained butt joint was cut along the tube axis into four equal pieces as shown in Fig. 1. The length of the welded tubes was approx. $300 \mathrm{~mm}$, the external diameter $45 \mathrm{~mm}$ and width of the walls 8.5 and $6.0 \mathrm{~mm}$ for " 0 " and " 1 " samples respectively.

Chemical composition of the samples was verified with the help of a spark spectrometer SpectroLab and the results are shown in Table 1. The investigated tubes were chosen from a bigger batch prepared for creep tests. After welding, one of them (sample " 0 ") turned out to be significantly different (taking into account magnetoacoustic properties) from the other samples so it was decided to investigate the issue. It is worth noting that the problematic tube was not prepared on purpose but was a result of procedure during which "something went wrong", so this is a case that can easily happen in industrial practice. The other sample ("1") was chosen arbitrarily for comparison. The microstructure of the VM12 steel tube base material is shown in Fig. 2. It is composed of lath martensite with numerous precipitates both at the prior austenite boundaries and at the lath boundaries. Visual observations (Fig. 3) confirmed the correct

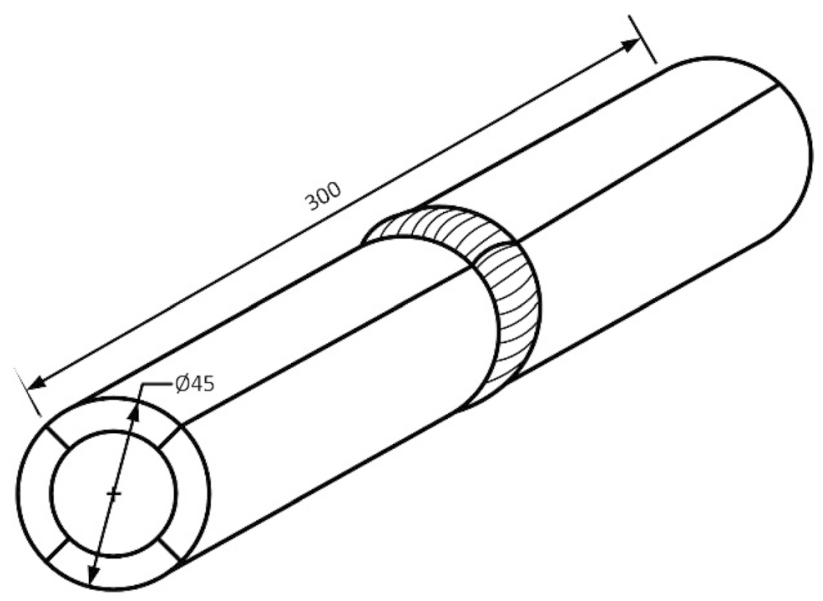

Fig. 1 Schematic view of the investigated samples 
Table 1 Chemical composition of the VM12 steel (base metal); $(\mathrm{wt} \%)$

\begin{tabular}{llllllllllll}
\hline $\mathrm{C}$ & $\mathrm{Si}$ & $\mathrm{Mn}$ & $\mathrm{P}$ & $\mathrm{S}$ & $\mathrm{Cr}$ & $\mathrm{W}$ & $\mathrm{Mo}$ & $\mathrm{Co}$ & $\mathrm{Nb}$ & $\mathrm{V}$ & $\mathrm{B}$ \\
\hline 0.11 & 0.45 & 0.34 & 0.003 & 0.0004 & 11.51 & 1.79 & 0.26 & 1.45 & 0.04 & 0.19 & 0.0013 \\
\hline
\end{tabular}

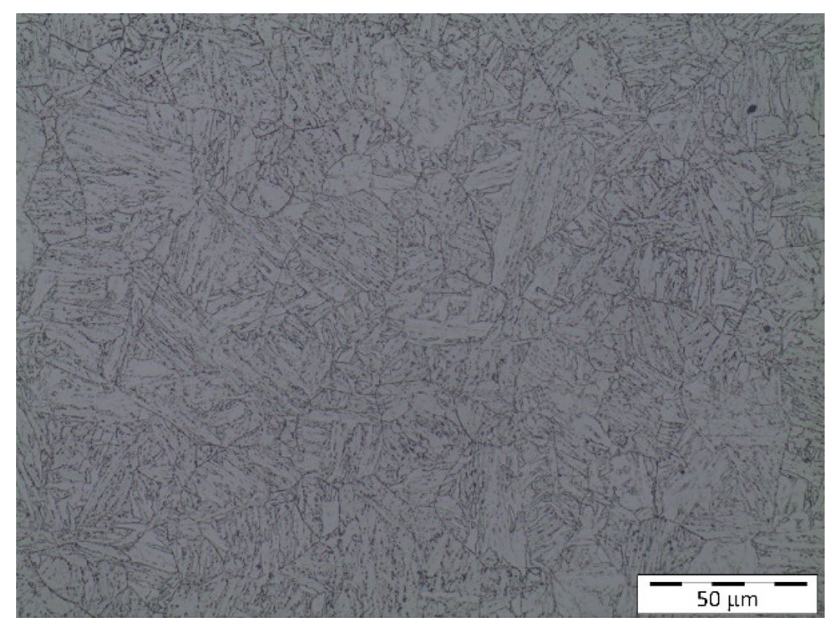

Fig. 2 Base material microstructure (VM12)

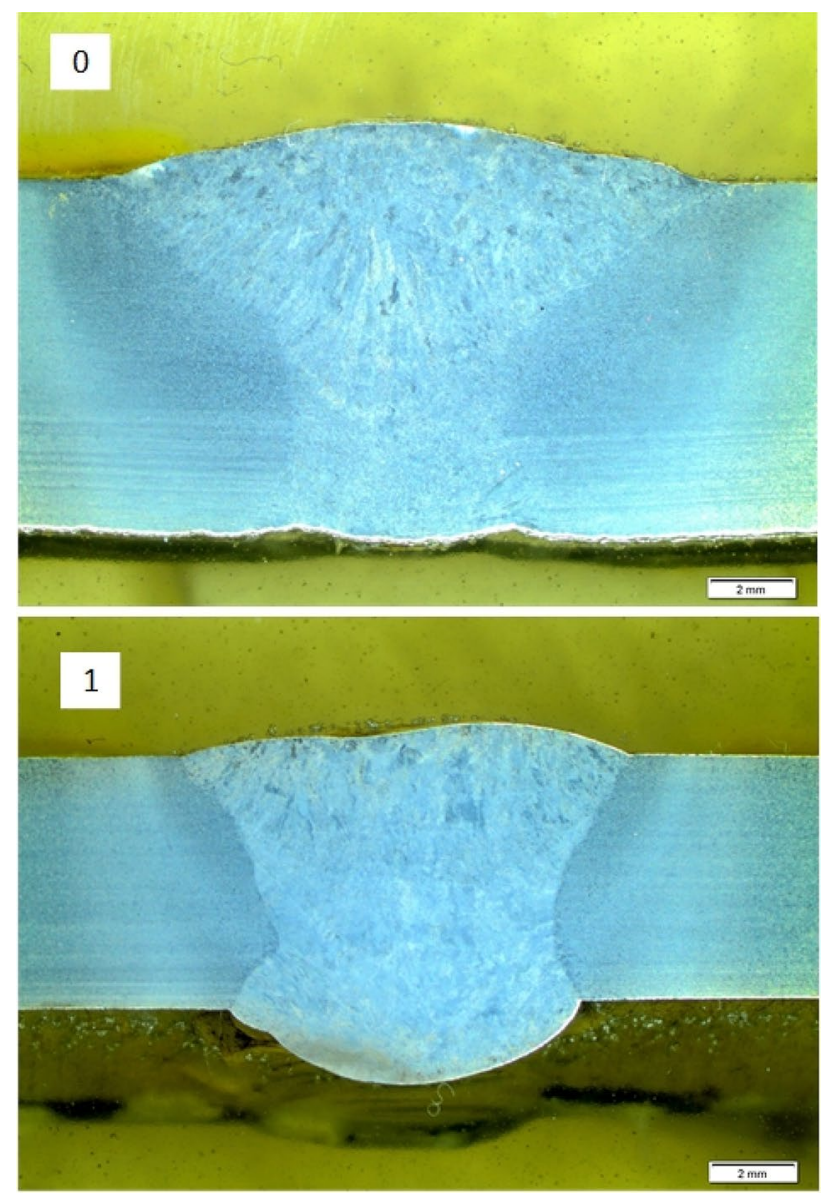

Fig. 3 Macroscopic view of the invstigated joints: "0" and "1" refer to the samples described in the text structure of welds with no observable imperfections. A small difference in shape of the weld seam cross-sections is of minor importance and may be due to the different thickness of the samples. After the welding all the samples underwent preliminary MAE signal measurements in order to verify the repeatability of the results measured for different samples from the same tube (it turned out to be the case). Then three out of four samples from each tube were subjected to the post weld heat treatment $\left(1 \mathrm{~h}\right.$ at $\left.770{ }^{\circ} \mathrm{C}\right)$ in order to decrease dislocation density, lower the residual stress level and obtain desired mechanical properties (tensile strength, impact resistance) as well as diminish the hardness of the weld seam to an acceptable level (below $320 \mathrm{HV}$ ). The samples that remained as-welded were named "0i" and "1i" (initial) and the heat treated ones "Of" and"1f" (final).

The samples made of X20CrMoV12.1 were cut out from a thick walled pipe and machined into the shape of long bars having dimensions of $140 \times 11 \times 5 \mathrm{~mm}$. All of the samples were austenitized at $1050{ }^{\circ} \mathrm{C}$ for one hour and then air quenched. One sample was left in the as-quenched state and the remaining five samples underwent tempering at $750{ }^{\circ} \mathrm{C}$ for various duration times (15, 30, 60, 120 and $240 \mathrm{~min}$ ). Since the process followed a well described tempering procedure, no microstructure investigations were made, especially due to the fact that the main feature that was expected to undergo important changes was the dislocation density, the analysis of which requires high quality TEM pictures. The evolution of dislocation density during tempering of martensitic steels was investigated in detail by other authors, se e.g. [17].

\subsection{Measurement Set}

The main challenge to deal with was the measurement of the signals from the weld seam area only especially for the cut-outs from the welded tubes. The problems arose from the fact that the samples were irregular in shape and the interesting area was only a small part of each sample. As the sound travels freely in samples made of steel, only the investigated region may be a source of the MAE signal. It had to be magnetised strongly as the phase, expected to be responsible for the observed difference in sample hardness, was tempered martensite which is a magnetically hard phase. The MAE signal was measured with the help of a set shown in Fig. 4.

The special feature of the electromagnet (2) used is the fact that its poles are made of small rods that can adapt themselves to irregular shapes of the samples and as a result increase the flux density inside the investigated 


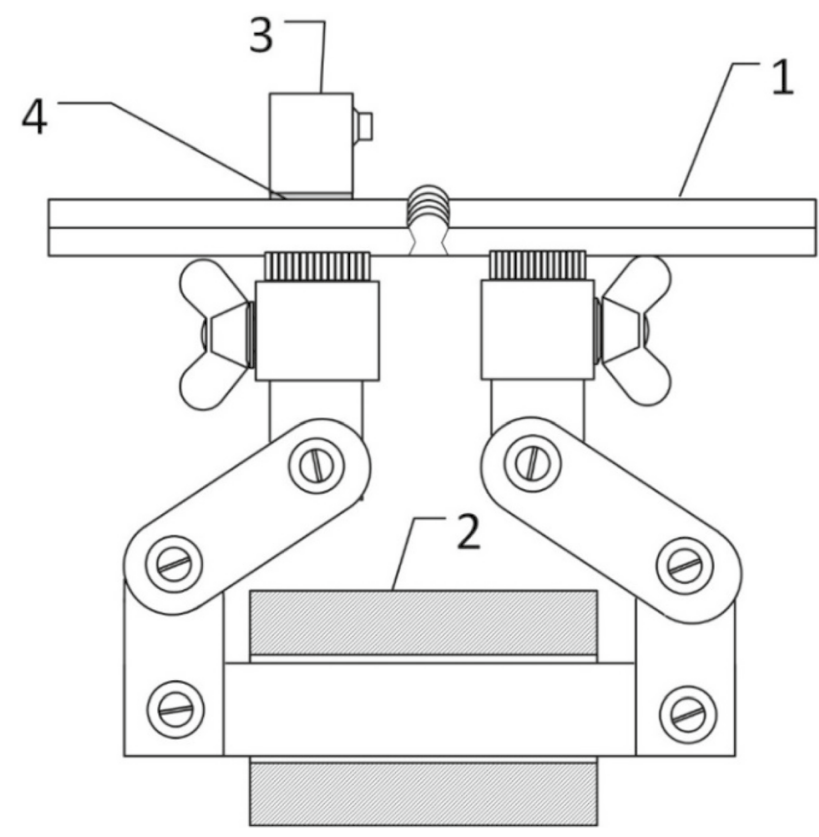

Fig. 4 Magnetising set. 1-sample, 2-electromagnet, 3-MAE transducer (PZT), 4-acoustic coupling

material (details of the device can be found in [18]). In addition to that, due to swivelling legs it has an adjustable pole distance, allowing for localized magnetisation of the material. The sample (1) was placed on the electromagnet with inner wall of the tube towards the poles in order to have free access to outer surface on which the MAE sensor was placed. The magnetising frequency was $1 \mathrm{~Hz}$ and the current was triangular in form. The sensor (3) used for the experiment was a wide band acoustic emission sensor manufactured by Physical Acoustic Company. In order to obtain a good signal quality it was coupled to the surface with the help of silicon grease (4). Both the magnetising current (triangular in form) and measurement process were controlled by the dedicated apparatus containing NI USB6353 multifunction device driven by the software written in the LabVIEW environment. The device allows for basic signal processing (calculation of rms-like envelopes), yet in order to perform pulse count analysis of the measured MAE noise signal after amplification was recorded as measured with sampling frequency $1 \mathrm{MHz}$. The combined amplification was $120 \mathrm{~dB}$, the $30 \mathrm{~dB}$ of which was realised with the help of a close to the transducer pre-amplifier.

The X20 samples were investigated with the help of the magnetising system described in [13], equipped with flat, unmovable poles and magnetizing probe encircling the sample. In the case of those samples, thanks to their regular shape it was possible to use the same setup to measure their magnetic properties (quasi static hysteresis loops).

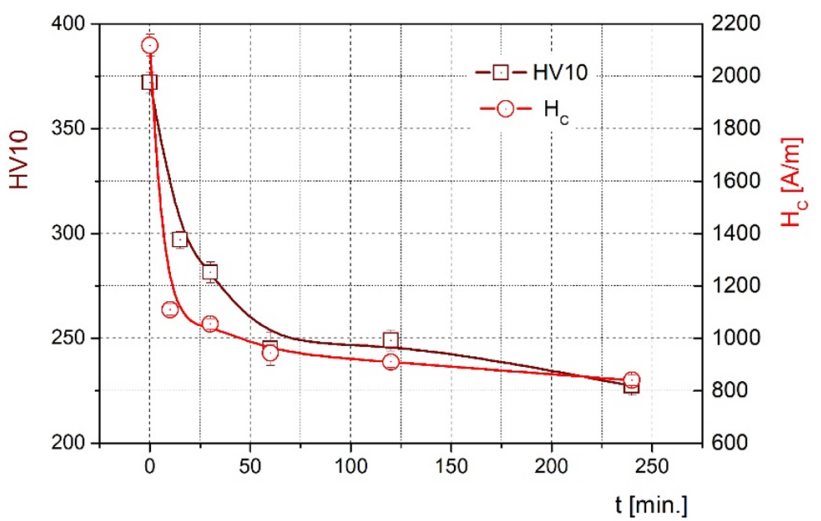

Fig. 5 Evolution of X20CrMoV12.1 samples properties during tempering: brown squares-hardness (HV10); red circles-coercivity $\left(\mathrm{H}_{\mathrm{C}}\right)$

Hardness laboratory tests were performed with the help of Future-Tech FV-700 hardness tester with $5 \mathrm{~kg}$ load. Hardness measurements are commonly used in industrial environments for the assessment of the quality of the PWHT of joints. However in that case an ultrasound hardness meter is normally used. Accordingly we have also performed such measurements across the polished seam face with the help of KrautKramer MIC-10 hardness meter.

The impact test was carried out on Charpy V samples with reduced dimensions (less than $5 \mathrm{~mm}$ wide), while the static tensile test was performed on round samples with an initial measuring diameter of $5 \mathrm{~mm}$.

\section{Analysis of Heat Treatment Process of X20CrMoV12.1 Grade Steel}

The as observed differences in weld metal and HAZ properties of the investigated welded tubes can be understood by investigation of changes introduced by the tempering process in high chromium creep resistant steels. The influence of tempering process on the MAE signal shed light on the reasons of such strong difference between signals obtained for two, supposedly similar welded samples. We have analysed the influence of tempering process on the MAE signal properties for P91 (result published in [16]) and X20CrMoV12.1 steel (investigated with the help of mechanical Barkhausen effect signal only in [19]). Here we present the results of the MAE signal measurements for X20 steel, as it is more similar to our case (and remain unpublished).

In Fig. 5 (squares) there is shown the change of hardness (HV10) as a function of tempering time (tempering temperature $\mathrm{T}=750^{\circ} \mathrm{C}$ ). As expected, the hardness starts to decrease as a function of tempering time right from the onset, and the decrease is very pronounced (about 40\%). This can be logically explained by the decrease in the dislocation density 
which is initially (non-tempered martensite) very high (of order $\sim 10^{15} \mathrm{~cm}^{-1}$ ) and after one hour of tempering decreases by the order of magnitude [17]. Very high dislocation density results in high hardness and internal stress level, both of which are more or less linearly dependent on the square root of dislocation density $[20,21]$. The change in the dislocation density during tempering correlates also qualitatively with the observed [19] decrease of the internal stress level. The dislocations are not only responsible for mechanical hardness of steel. They are also one of main obstacles to the motion of domain walls (together with precipitates and grain boundaries) influencing the coercivity (magnetic hardness parameter) and squareness of hysteresis loops as can be seen in Fig. 6. There is also a characteristic feature of all (except the non-tempered) loops-they intersect roughly in the same point. Such feature was observed in [22] where it was explained with assumption that hysteresis loops are affected only by different levels of residual stress after tempering at various temperatures. The discrepancy observed for the non-tempered sample may be due to the fact that in this case the material was not magnetically saturated.

The most pronounced change of magnetic properties takes place in the first $15 \mathrm{~min}$ of tempering, what is in agreement with abrupt change of hardness. The observed changes of hysteresis loop shape can be characterised by coercivity (Fig. 5, circles) which steadily decreases, down to $40 \%$ of the initial value. Such a pronounced change of coercivity indicates that dislocation tangles are the most efficient pinning sites in the investigated material. The observed change saturates for longer times, and it was observed that for samples tempered at higher temperature $\left(\mathrm{T}=780^{\circ} \mathrm{C}\right)$ the trend changed for longer times due to the opposing influence of increasing precipitate size $\left(\mathrm{M}_{23} \mathrm{C}_{6}\right)$ which become effective pinning sites after reaching the diameter comparable to domain wall width $(\sim 100 \mathrm{~nm}$ for steel).

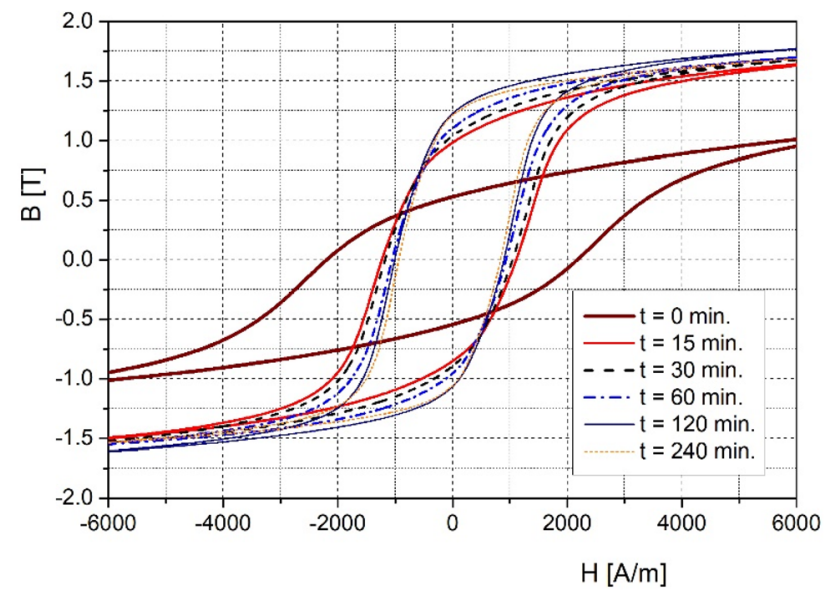

Fig. 6 Magnetic hysteresis loops of X20CrMoV12.1 for samples subjected to tempering
The changes of magnetisation dynamics affect the MAE signal, which is generated by processes of creation/ annihilation of closure domains and subsequent movement of $90^{\circ}$ domain walls. Those processes take place at magnetic field values corresponding to "knee" areas of hysteresis loops and generally strongly depend on the rate of change of magnetisation in that range of field intensity. The obtained MAE signals (rms-like envelopes) for all the samples are plotted in Fig. 7. As can be seen the observed change of the signal envelopes is very pronounced-in fact for the martensitic sample the signal is barely detectable and heavy averaging ( 3 measurements of 5 periods each with subsequent 50 point smoothing) necessary in order to obtain a passable envelope. Starting from $15 \mathrm{~min}$ of tempering the signal becomes clearly visible and its intensity grows steadily with tempering time. Quantitatively the signal can be characterised by the integral of signal envelope after background level subtraction (rms signal rule) which we will call the MAE signal intensity:

IntUa $=\int_{-I_{\text {MAX }}}^{I_{\text {MAX }}} \sqrt{U a^{2}(I)-U_{\text {noise }}^{2}(I)} d I$

Appropriate subtraction of the noise level is substantial, especially in the case of low intensity signals, as it influences very strongly the obtained signal intensity. It is however necessary in the case of industrial environment due to changing noise conditions [16]. The obtained intensities are plotted in Fig. 8. as a function of tempering time. The change in the signal intensity is very big as the signal increases more than six times, and what is also very important, the change is observed clearly for the whole range of tempering time-there is still more than $20 \%$ increase of the signal intensity between 120 and 240 min of tempering, which is not the case for either coercivity or hardness. Being so the MAE signal preserves

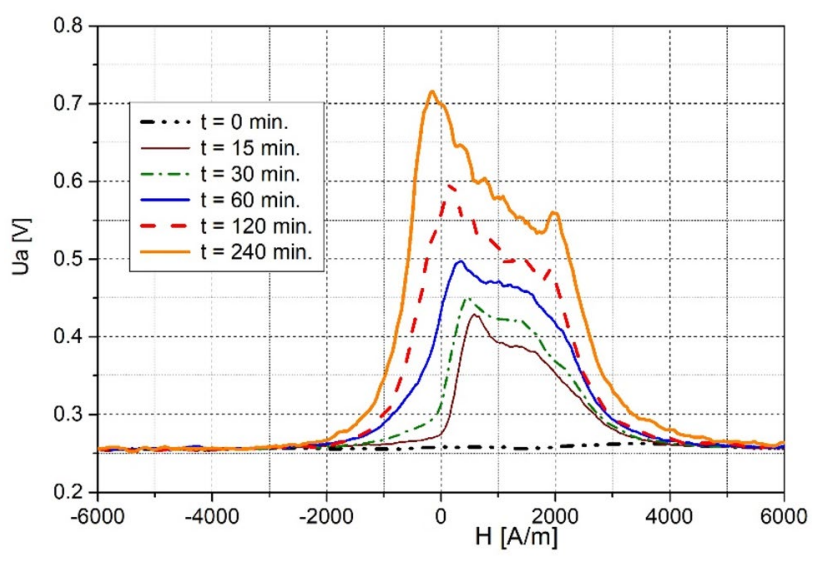

Fig. 7 The MAE signal envelopes-X20CrMoV12.1 samples subjected to tempering 


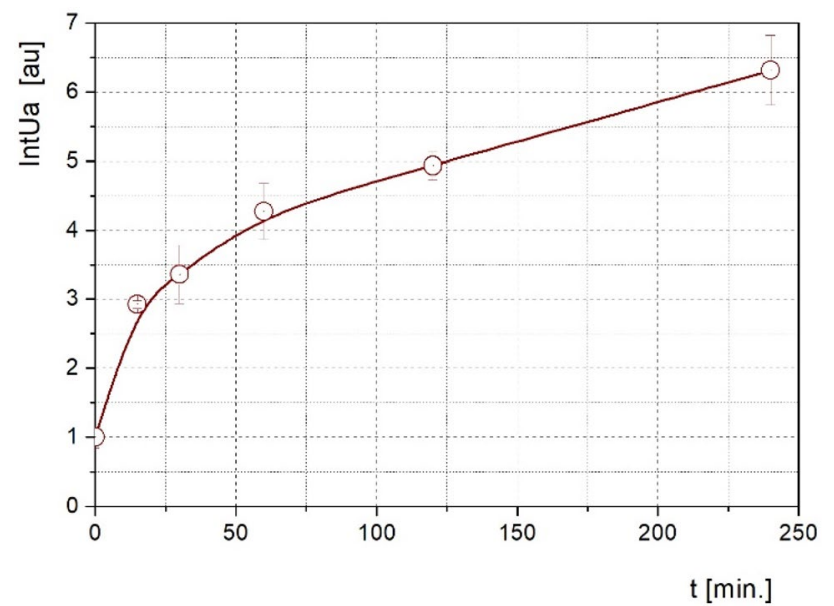

Fig. 8 The MAE signal intensity as a function of tempering time$\mathrm{X} 20 \mathrm{CrMoV} 12.1$

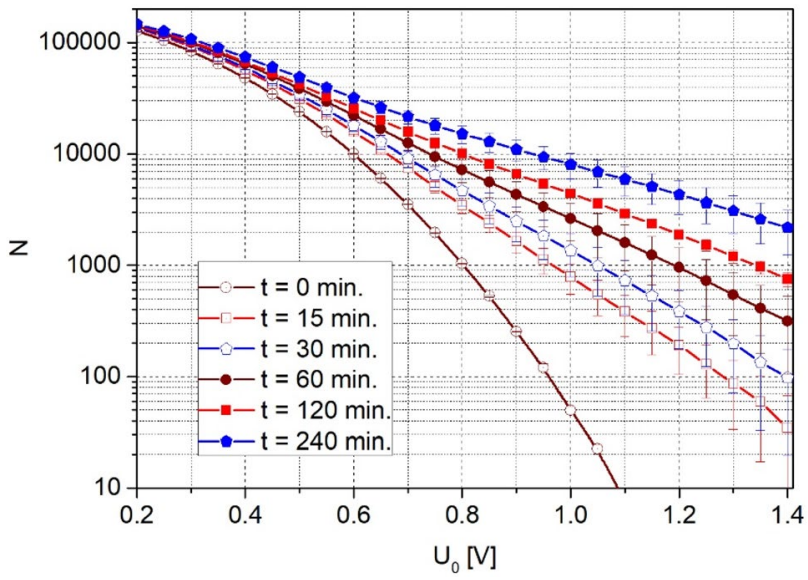

Fig. 9 Total pulse count $(\mathrm{N})$ as a function of threshold voltage$\mathrm{X} 20 \mathrm{CrMoV} 12.1$ samples subjected to tempering

its sensitivity to heat treatment induced changes in much broader range than other two parameters.

The analysis of noise signals can also be performed with the help of pulse height analysis. Figure 9 shows the total pulse count $(\mathrm{N})$ as a function of the threshold voltage (only the pulses of higher than threshold value were counted - the count was performed during software numerical post processing with the help of the dedicated procedure in LabVIEW environment). The difference between samples becomes more and more pronounced for higher threshold values, yet one has to take into account that with the decrease of total pulse count the stochastic uncertainty increases. Being so, in order to find the best threshold voltage level one has to take into account both the sensitivity and reliability of the obtained results. In addition to that the total pulse count is quite sensitive to the background

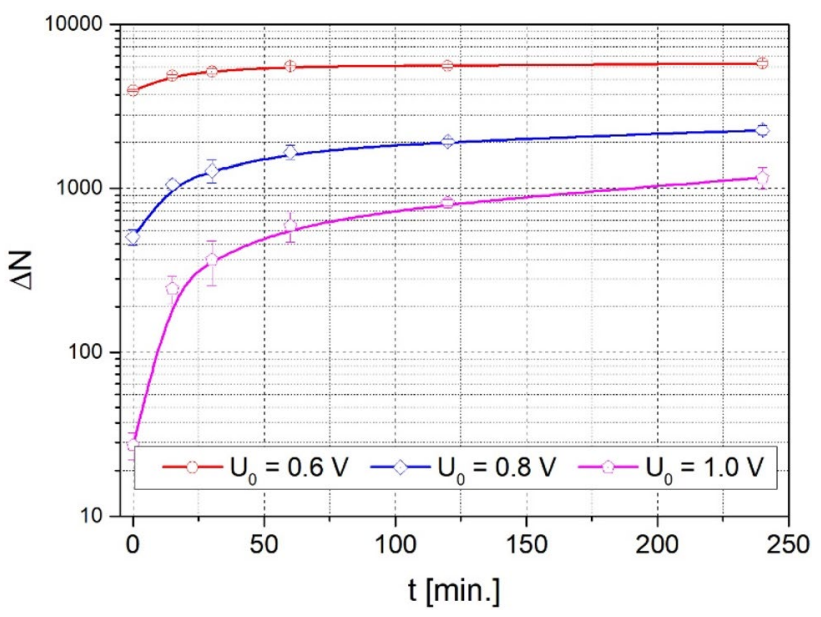

Fig. 10 Pulse height distribution $(\Delta \mathrm{N})$ as a function of threshold voltage (high threshold values)-X20CrMoV12.1 samples subjected to tempering

noise level. It turns out that we can obtain much less noise sensitive parameter via analysis of pulse height distribution-calculating the number of pulses that fit in between two consecutive threshold levels distant by a given value $(\Delta \mathrm{N}=0.05 \mathrm{~V}$ in our case). Figure 10 shows the dependence of $\Delta \mathrm{N}$ parameter on the tempering time for three various threshold voltage levels.

Since the difference in behaviour of the that parameter for various threshold levels is very pronounced, the picture shows the results for the threshold voltage $0.6 \mathrm{~V}$ and higher (levels exceeding maximum background noise pulses). For such threshold voltage levels the obtained results behave in a monotonous way, but there is a strong difference in the dynamics of change of $\Delta \mathrm{N}$ parameter for different threshold levels starting from increase by more than $40 \%$ for $\mathrm{U}_{0}=0.6 \mathrm{~V}$ through more than $400 \%$ for $\mathrm{U}_{0}=0.8 \mathrm{~V}$ up to $4000 \%$ for $\mathrm{U}_{0}=1.0 \mathrm{~V}$, yet for the last case with the uncertainty exceeding $30 \%$. Being so probably the most appropriate (from the practical point of view) would be the choice of $\mathrm{U}_{0}=0.8 \mathrm{~V}$ as in this case the uncertainty is of order of $15 \%$ and the minimum count number is higher than 500 pulses. Stronger relative increase in number of higher pulses is not surprising as with the decrease of dislocation density the number of pining sites (dislocation tangles) diminishes and at the same time the average distance between pinning site increases. Being so, domain walls, once unpinned, will travel for longer distances and as a result stronger acoustic pulses will be generated. One might expect that for small pulses the $\Delta \mathrm{N}$ should decrease, and it is actually the case as shown in Fig. 11. For very small threshold values $\left(\mathrm{U}_{0}=0.2 \mathrm{~V}\right)$ the pulse count decreases by $12 \%$. For $\mathrm{U}_{0}=0.3 \mathrm{~V}$ the changes become non-monotonous, yet there is small overall decrease during the whole tempering process $(\sim 7 \%)$, while for $\mathrm{U}_{0}=0.4 \mathrm{~V}$ the final effect is small increase of pulse number 


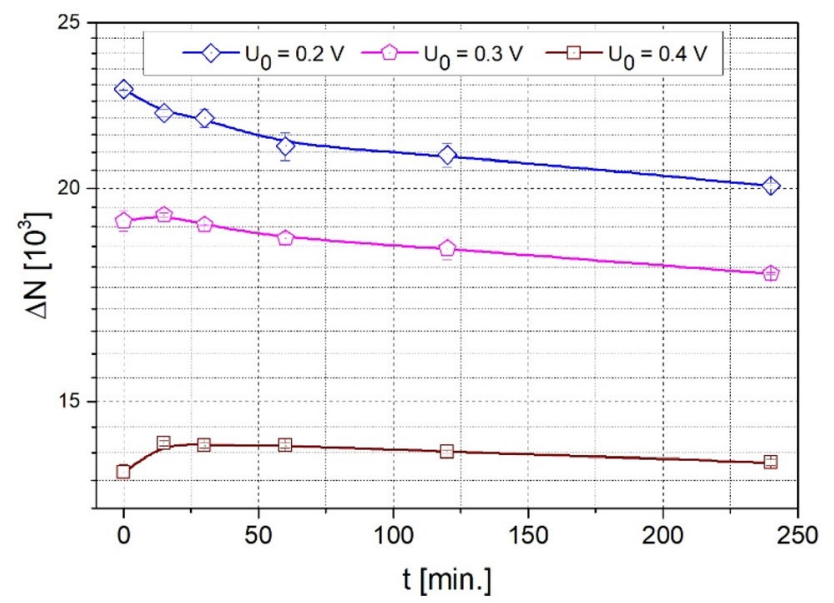

Fig. 11 Pulse height distribution $(\Delta \mathrm{N})$ as a function of threshold voltage (low threshold values)-X20CrMoV12.1 samples subjected to tempering

$(\sim 1.3 \%)$. The counts obtained for such low threshold levels should not be taken into account for exact quantitative analysis since the number of pulses counted is strongly dependent on the background noise pulse numbers (which may reach as high as $0.5 \mathrm{~V}$ ). However in laboratory conditions, with stable background noise levels, the observed trends qualitatively confirm the gradual disappearance of small pulses during tempering, what is in agreement with the decreasing concentration of pinning sites (dislocation tangles).

The fact that non-tempered martensitic steels exhibit so very low level of MAE signal intensity might not seem obvious. The higher the number of dislocation tangles the higher should be pulse count, even though those pulses should be shorter (in time domain) due to the strong pinning DWs should jump abruptly and result in a measurable signal. In reality for the as-quenched sample the observed pulses are very weak, such behaviour might be explained by the model analogous to the one used for nanocrystalline materials coercivity prediction (in which the dominant pinning mechanism is based on anisotropy energy minimisation)_random anisotropy model [23]. The original model predicts than in the case of a DW intersecting with many nanocrystalline grains after each jump its energy is far from minimum, yet its oscillations caused by DW displacement are very small. Pinning on the other hand is not dependent on the value of anisotropy energy but on the change of it resulting from the DW jump. In our case, instead of the magnetocrystalline, stress induced anisotropy is averaged. Domain walls, as described by Kersten model [24], are pinned by stress fields around the dislocations. However every domain may span the area of several deformation fields. During a DW jump some parts of the domains are transferred to more, some to less favourable positons, as a result the elastic energy change is small,

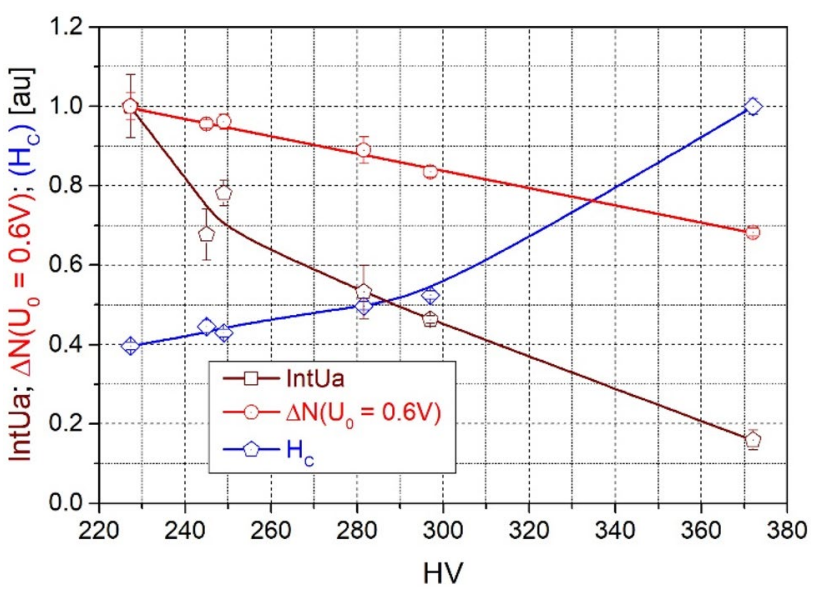

Fig. 12 Correlation between magnetoelastic properties and hardness for the X20 steel samples

hence the pulses generated are barely detectable. The averaging does not affect magnetic Barkhausen noise (BN) signal in the same way as in that case the pulse amplitude is dependent on the magnetic flux change (not on magnetoelastic energy). Being so the most important feature of $\mathrm{BN}$ signal for martensitic steels is shift towards higher magnetizing field values [25].

Figure 12 shows the correlation between magnetoelastic properties (IntUa, $\Delta \mathrm{N}\left(\mathrm{U}_{0}=0.6 \mathrm{~V}\right)$, coercivity) and hardness for the X20 steels. The as plotted dependence between coercivity and hardness shows that the assumption regarding the dislocation concentration being the main source of both coercivity and hardness works well for the samples tempered for at least $15 \mathrm{~min}$-both parameters decrease during tempering the obtained dependence is almost linear $(r>0.986)$. In the initial phase of tempering the relative decrease of coercivity is faster than that of hardness. The difference may not be extremely big yet clearly noticeable, what's more it is not incidental as we have observed it previously for P91 steel (unpublished data). Such behaviour can be explained by the secondary hardening due to the strong precipitation of very fine carbides of alloying elements [26]. Such process changes the softening rate but does not affect coercivity as the precipitates are too small to interact strongly with DWs. As for the correlation between MAE signal parameters there is monotonous decrease of the IntUa parameter as a function of increasing hardness in agreement with the concept of stress anisotropy averaging. As for the pulse count $\Delta \mathrm{N}$ the behaviour differs for different threshold levels. For $\mathrm{U}_{0}=0.2 \mathrm{~V} \Delta \mathrm{N}$ increases with hardness then there is non-monotonous region and finally strong decrease of $\Delta \mathrm{N}$ is observed. Interestingly, for some threshold voltage $\left(\mathrm{U}_{0}=0.6 \mathrm{~V}\right)$ the dependence is linear, what might be beneficial from the metrological point of view. 


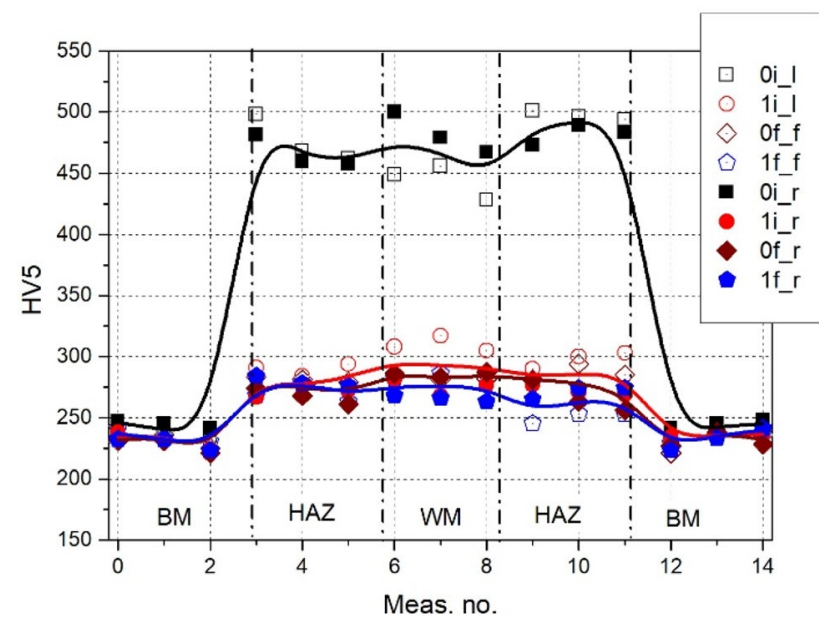

Fig. 13 Hardness (HV5) measured across the weld seam for the investigated samples: i -without PWHT, f-after PWHT; _f-face side,_r—ridge side

\section{Weld Material Properties Investigation}

\subsection{Mechanical Properties}

The results of hardness laboratory measurements (HV5) performed across the weld seam are shown in Fig. 13. Empty symbols indicate results obtained for the area close to the seam face, full symbols are for the ridge area and lines show averaged (face/ridge) values. As it can be easily seen, hardness of " $0 \mathrm{i}$ " sample is completely different than those observed for the other samples. Such high values are normally observed for the non-tempered martensite. Being so it is not surprising that subsequent heat treatment (tempering) results in a very pronounced decrease of hardness (sample "0f"). The second hardest material is "1i" sample (as welded) yet the values obtained for that sample are not much higher than for the heat treated samples (hence small influence of heat treatment- " $1 \mathrm{f}$ ")-it suggests that the initial dislocation density in that case is close to the one characteristic for tempered martensite. Such differences are probably due to the small differences of the heating/cooling dynamics during the welding process of samples " 0 " and "1" [27].

For the as-welded samples there is a difference between ridge and face area hardness which practically disappear after annealing. For the " $1 \mathrm{i}$ " sample seam face hardness is higher by about $10 \%$ than the ridge area one. This is a typical behaviour for correctly performed multipass welding. In such a case the first pass is often preceded by preheating and in addition to that the second pass acts as a kind of heat treatment on the first one and so on. Such behaviour is not observed for " $0 \mathrm{i}$ " sample. The difference is small and of opposite sign (to both the other samples and theoretical predictions for multipass welding) which suggests that the preheating temperature for the first pass was too low resulting in high cooling rate $(\mathrm{R})$, which can be determined for low number of passes from the formulae:

$R=2 \pi k \rho C\left(\frac{h}{H_{\text {net }}}\right)^{2}\left(T_{C}-T_{0}\right)^{3}$

where $\mathrm{h}, \mathrm{k}, \rho$ and $\mathrm{C}$ stand for thickness, thermal conductivity, density and specific heat of base material. $\mathrm{H}_{\text {net }}$ is the heat input, and $\mathrm{T}_{\mathrm{C}}$ and $\mathrm{T}_{0}$ temperatures stand for the actual temperature and for the initial one (preheating temperature). Too high cooling rates may result in martensite formation and both brittleness and susceptibility to hydrogen embrittlement [28]. The following heat treatment succeeded however in obtaining the required properties of weld seams in both cases.

The results of ultrasound hardness measurements are shown in Fig. 14-they are quantitatively similar to laboratory results, but there are some minor differences. In this case the hardness values are almost identical for tempered samples but have high scatter ( 10\%). Similarly to laboratory tests the lowest hardness is attributed to " $0 \mathrm{f}$ " sample. The tempered sample " $1 \mathrm{f}$ " is a bit harder-especially in weld material (WM) area. As it was observed in laboratory tests the hardest sample is " $0 \mathrm{i}$ ". The difference is however smaller than in the case of laboratory measurements. Concluding it may be said that, to no surprise, industrial method of hardness assessment is somewhat less sensitive than the laboratory tests.

The measurements of yield strength (Rm) and absorbed energy (KV) have also been performed and the results are shown in Fig. 15. Both the impact test and the static tensile

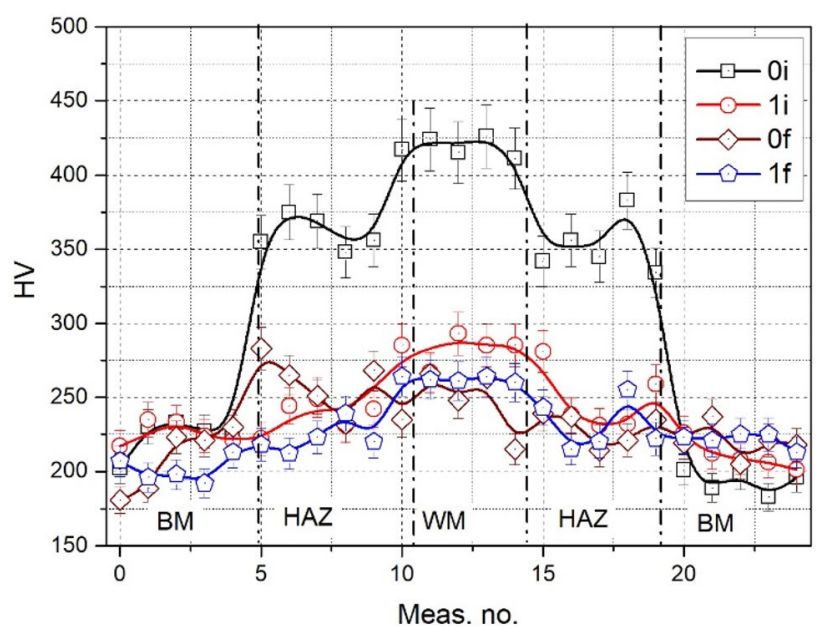

Fig. 14 Results of ultrasound hardness measurements across the weld seam 


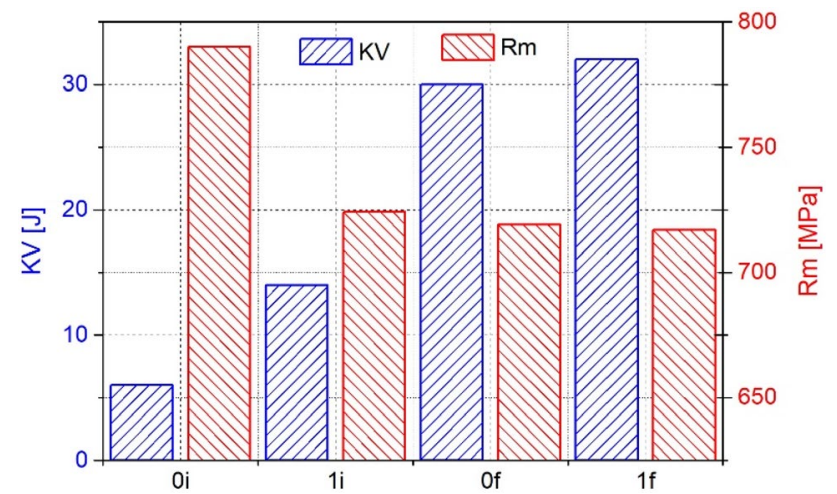

Fig. 15 Mechanical properties of the investigated samples: absorbed energy (KV) and yield strength (Rm)

test due to the scarce amount of available material were carried out on non-standardized samples.

The required VM12 steel absorbed energy for standard samples is $27 \mathrm{~J}$. The tested as-welded samples were characterized by (renormalized) absorbed energy much lower than the minimum requirements. Such behaviour is usually related to the presence in the weld seam of non-tempered martensite, having both high hardness and small toughness. Post welding heat treatment of the analysed welds resulted in dislocation density decrease, ductility improvement and as a result increase in absorbed energy - high enough for both samples to meet the requirements.

The tensile strength of the welded samples under investigation, both as welded and heat treated, was higher than the requirements for VM12 steel, for which the tensile strength should within the range of $620-850 \mathrm{MPa}$. The undoubtedly highest tensile strength of " $0 \mathrm{i}$ " sample is the additional confirmation of the presence of non-tempered martensite characterised by high tensile strength. The PWHT process resulted in a relatively small decrease of tensile strength, slightly exceeding $9 \%$ in the case of " 0 " sample.

\subsection{The MAE Signal Measurements}

The observation of different magnetoelastic properties of one of welded pipes came as a surprise during preliminary investigation of samples prepared for accelerated creep tests. They were cut outs from several welded superheater tubes for which MAE signal properties for the initial (before creep tests) conditions were to be analysed. The first tests performed for the as welded tubes showed that the signals for all but one tube are fairy similar, however cut-outs from that tube differed from the rest very significantly. Examples of MAE signal envelopes obtained for two tubes, chosen for further investigations (both aswelded and after heat treatment) are shown in Fig. 16. This time the plots are shown as a function of magnetising

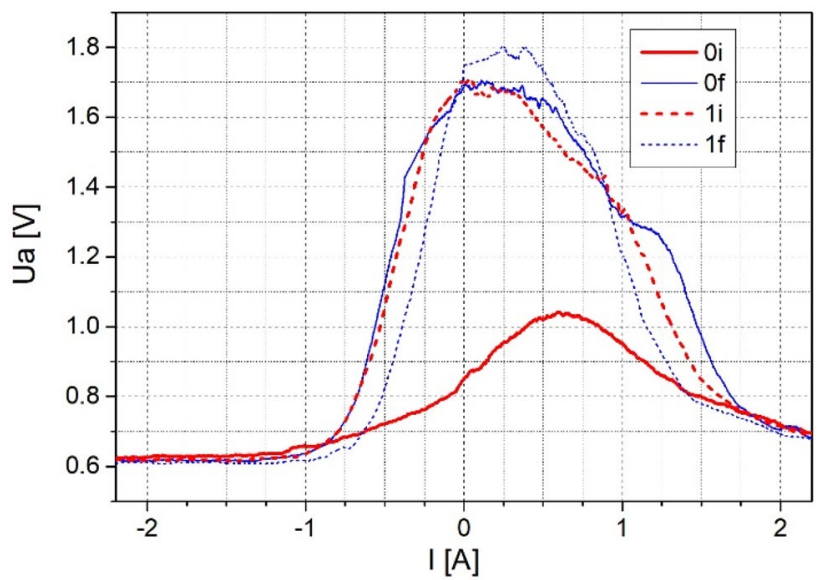

Fig. 16 The MAE signal envelopes for the investigated samples

current instead of magnetic field due to a complex geometry of the magnetising setup disabling exact assessment of the field values. One can however assess from the current at which MAE signals saturate that $1 \mathrm{~A}$ is equivalent roughly to $2 \mathrm{kA} / \mathrm{m}$.

As can be seen the difference is very significant for the signal obtained for the as-welded samples. Not only the intensity of the signal obtained for the as welded " 0 " sample is significantly lower than the one for the sample " 1 ", but also the maximum of the signal is shifted towards higher magnetic field values, what suggests presence of significant amount of magnetically hard phase, presumably non-tempered martensite. The following heat treatment results in very pronounced changes of the MAE signal for " 0 " sample. The intensity of the signal increases considerably and the position of the signal envelope maximum shifts towards lower magnetic field values. Much less significant changes take place in the case of the sample "1", the amplitude of the signal is higher but the width of the maximum is smaller so that the intensity (IntUa) differs very little.

The signals obtained for both samples, before and after heat treatment are compared in Fig. 17. It can be seen that overall MAE signal intensity (IntUa) increases by almost $70 \%$ after heat treatment for " 0 " sample, whereas the change for sample " 1 " is almost unnoticeable. The amplitude of the MAE signal envelope changes even more strongly - there is a $90 \%$ increase of peak-to-peak voltage for "0" sample and even for the sample " 1 " for which the intensity is almost unaffected the increase of order of $10 \%$ due to heat treatment is observed. However the peak-to peak voltage is usually less reliable as the scatter of the measured values is quite high (in our case over 10\%). Any mechanical vibration may result in a short lasting acoustic pulse which modifies the intensity by a few percent, but changes the amplitude completely. Such pulses are easily discernible, but they are not easy to remove. They cannot be filtered out since via magneto-mechanical 


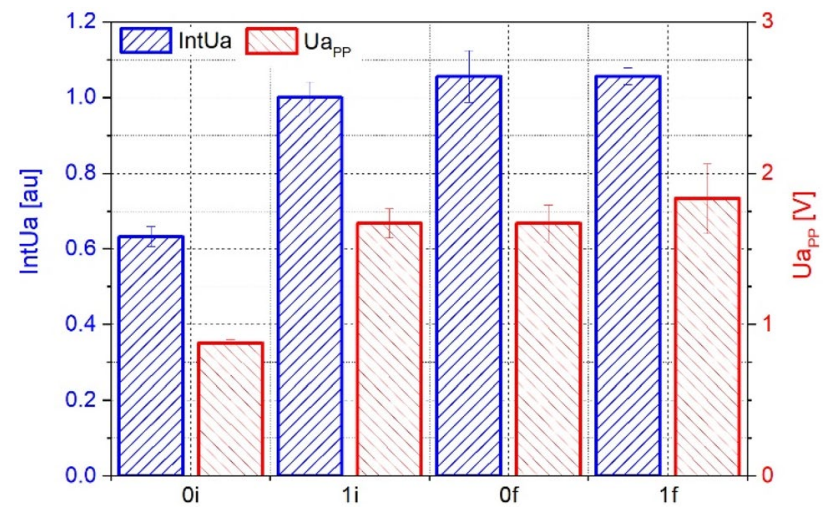

Fig. 17 The MAE signal intensity for the investigated samples (IntUa) and peak-to-peak value for the MAE envelopes

coupling they interact with domain walls generating noise of similar spectrum as the original MAE signal.

As it was shown in the paragraph regarding heat treatment of as quenched X20CrMoV12.1 another way of signal properties analysis is the pulse count analysis. Figure 18 shows the dependence of count rate (counts per time unit) for MAE signal obtained for " 0 " samples before and after heat treatment on time and threshold voltage $\left(\mathrm{U}_{0}\right)$. As can be seen, for the as-welded sample the signal is much weaker for all threshold levels. The relative change of count rate is however much more pronounced for the range of high threshold voltages. On the other hand the total pulse count falls rapidly down for higher pulses, hence the choice of the best threshold is a question of compromise. The surfaces like the ones in Fig. 18 characterize the pulse height distribution in the most detailed way, yet in order to use them in practice one has to find adequate quantifying parameters. Being so, the total pulse count $(\mathrm{N})$ for all four samples as a function of threshold voltage was calculated and then number of pulses of height fitting in between two threshold levels (voltage difference $0.05 \mathrm{~V})$ was determined $(\Delta \mathrm{N})$. The results of calculations are shown in Fig. 19. It is clear that the "0" sample differs from the others, no matter which threshold value one chooses, and the change introduced by the heat treatment is substantial. As for the sample " 1 " the change is not obvious as for the small threshold values one observes decrease and for the $\mathrm{U}_{0}=3.5 \mathrm{~V}$ trend is changing. It is even more clearly visible for 4.0 and $4.5 \mathrm{~V}$ but it neither can be compared with " $0 \mathrm{i}$ " sample (as there are no pulses of such height) nor treated as reliable results (as the scatter gets very big).

In order to verify the existence of correlation between the magnetoelastic and mechanical properties for the welded samples the latter ones (normalized values) were plotted as a function of the MAE signal intensity IntUa (the correlation with $\mathrm{Ua}_{\mathrm{pp}}$ was somewhat poorer) in Fig. 20. As can be seen all the parameters behave monotonously_-hardness

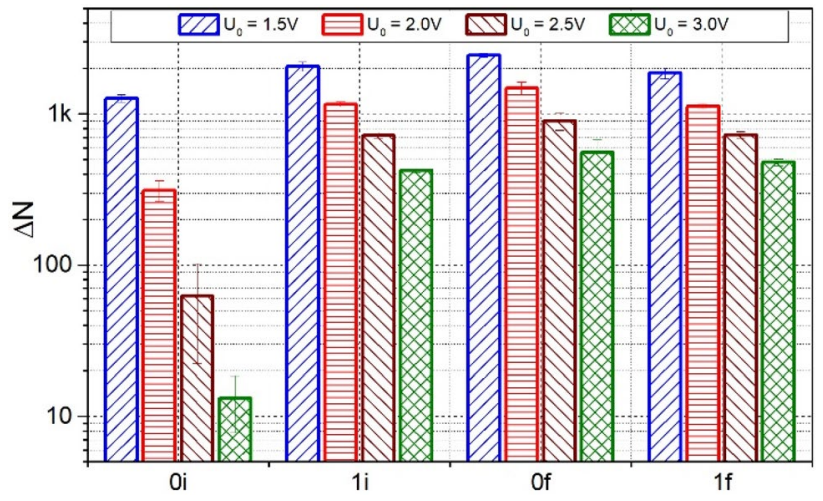

Fig. 19 Comparison of pulse counts for different pulse heights (threshold voltage step $0.05 \mathrm{~V}$ )

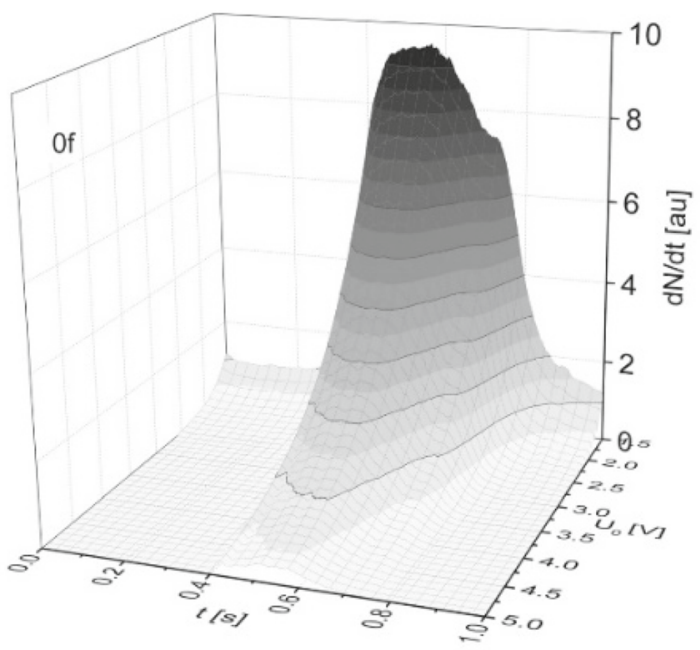

Fig. 18 Pulse count rate for various threshold voltage levels for "0" sample before and after PWHT 


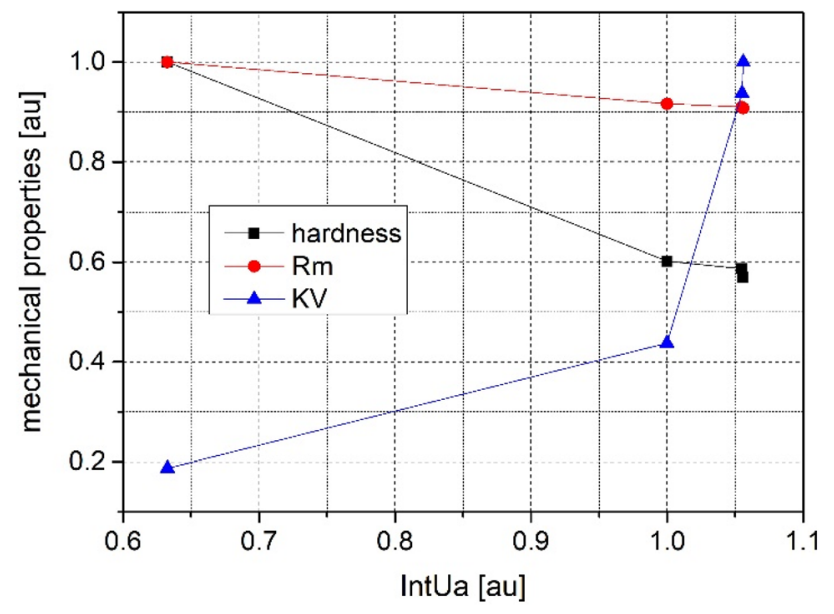

Fig. 20 Normalized values of mechanical properties (hardness, Rm, $\mathrm{KV}$ ) as a function of the MAE signal intensity (IntUa)

and yield strength decrease whereas toughness increases. However, only in the case of the two former ones the correlation is roughly linear $(r>0.99)$ suggesting the same kind of dependence on microstructural parameter in question i.e. dislocation density) which undergoes a very strong change during the PWHT process).

\section{Metrological Issues}

The MAE signal potential for the microstructure and stress level investigation has been recognised for a long time now. Yet the common problem with the measurements of that signal is the supposedly low repeatability of measurement results. This is partially true, in fact the main issue is the quality of contact between the MAE probe and the sample. One has to take much more care of contact than in the case of ultrasound tests or acoustic emission (due to cracking) measurements as in both cases we are mainly interested in the signal detection (simple YES/NO problem) and time of arrival determination. On the contrary in the case of the MAE measurements one must determine precisely the signal intensity. It is not, like many people suggest, impossible (in our laboratory for flat samples we normally obtain standard deviation of measurement results of order of $3 \%$ even if the measurement set is completely dismantled in the meantime). It requires however reasonable experience and sometimes much patience. Unfortunately the carelessly obtained results may differ more than $50 \%$ what makes them useless for the material properties investigation. Previously [10] we have proposed the method based on the measurement of the noise caused by the airflow (generated with the help of a pump) incident

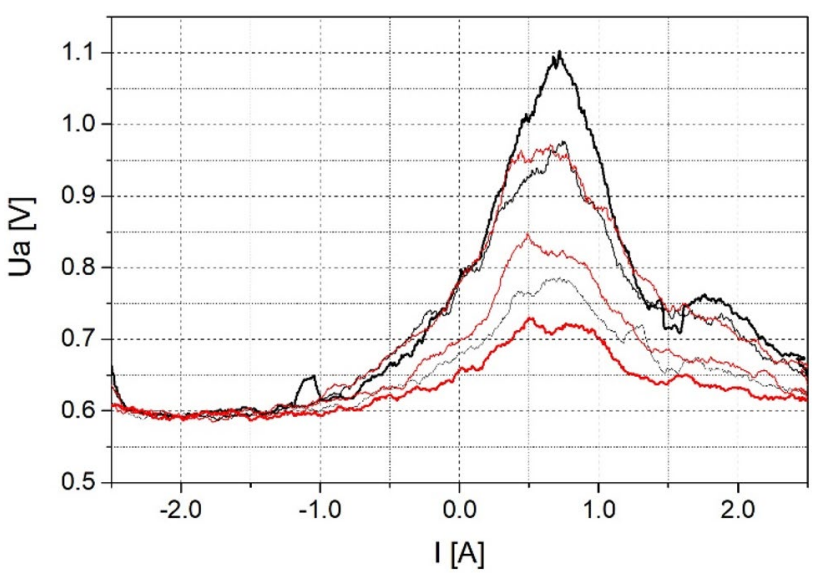

Fig. 21 The MAE signals envelopes obtained for different contact quality - "0" sample, weld area

on the surface of investigated object that might be used for contact quality evaluation. This method will however not work for the tubes with relatively small diameter (as compared with pipelines) since the intensity of the generated noise is strongly dependent on the shape of surface over which the air flows.

Being so we propose a method based on the determination of the ratio of signals measured for the weld and base material (changing the position of the electromagnet) without changing the MAE probe position. From our experience we may state that the relative position of the probe and electromagnet in a case of relatively small samples (20-30 cm long) is irrelevant, but for long pipelines the measurements should be performed in a predetermined geometry. In order to test our method we have made measurements for various contact qualities, even for a very poor contact (made such on purpose). The results of the measurements obtained for WM area of "0i" sample are shown in Fig. 21. As It may be observed the results differ so much that one could not hope to tell anything about the investigated material on the basis of them. Similar scatter of results however is observed for the signals measured for the base material of the same sample. Figure 22 shows the obtained intensities for the chosen locations (weld and base material) on both investigated tubes before the heat treatment. As can be seen the intensity of the signal cannot be determined precisely as the standard deviation reaches over $30 \%$. On the other hand the ratio of the intensity measured for the base metal to the one obtained for weld is very stable (standard deviation less than $4 \%$ ). Even the ratio of peak to peak voltage is quite stable (less than $9 \%$ ). Such results show that performing measurements in two different locations, changing only the electromagnet position, is a reliable way of the signal intensity assessment. 


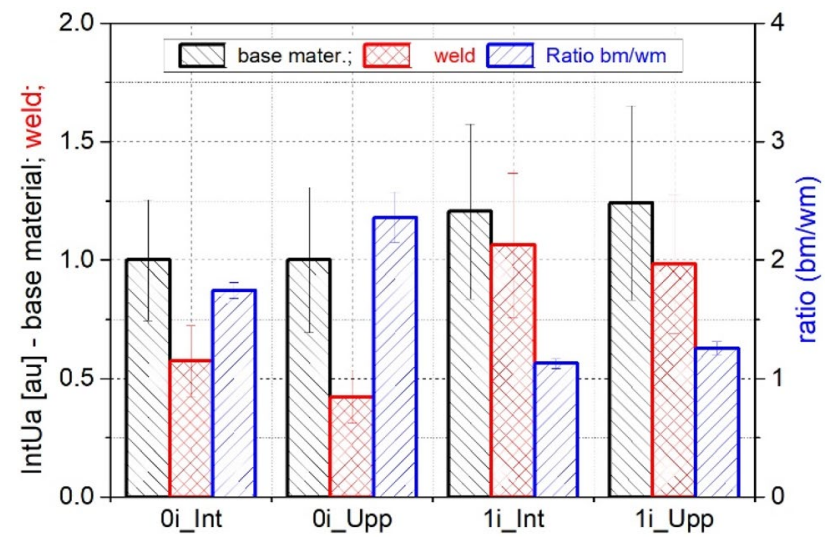

Fig. 22 Comparison of scatter in direct measurement results, both in weld and base metal areas with the one for obtained for their ratio

\section{Conclusions}

The MAE signal is very sensitive to the presence of non-tempered martensite in high chromium steel. It is so because the martensitic phase is a magnetically very hard hence the rate of change of magnetisation, on which the MAE signal intensity is dependent, is low. Also due to the very high concentration of pinning sites and small magnetoelastic energy released during the DW jumps the MAE signal consists of very small pulses. Being so, even though it is not possible to magnetize strictly the area composed of non-tempered martensite, the change induced by its presence is still easily detectable. The MAE signal has been used in various laboratory investigations for more than 40 years now [29-31], but still lacks industrial application. In our opinion the main deterrent, i.e. supposedly very low repeatability of the signal, with patience and practice it is not an unsurmountable obstacle. However, in order to make it welcome by industry it is necessary to make it less user dependent. We propose here an approach based on the relative measurements. In such a way we make the measurement independent on contact quality which stays the same during both measurements (weld material and base material). This approach makes also the method less dependent on the variation of wall thickness which may otherwise influence to some degree the signal. The dependence on the wall thickness is not very strong but for relative measurements it almost vanishes as both measurements are affected roughly in the same way.

The results presented here cannot be regarded as a systematic study of possible weld imperfections yet it demonstrates that in the case of non-tempered martensite presence inside the weld it can be easily detected. As with the progress of tempering the rate of the MAE signal change decrease a detailed analysis of signal parameters would be necessary to categorise the samples in later stages of PWHT.
Open Access This article is licensed under a Creative Commons Attribution 4.0 International License, which permits use, sharing, adaptation, distribution and reproduction in any medium or format, as long as you give appropriate credit to the original author(s) and the source, provide a link to the Creative Commons licence, and indicate if changes were made. The images or other third party material in this article are included in the article's Creative Commons licence, unless indicated otherwise in a credit line to the material. If material is not included in the article's Creative Commons licence and your intended use is not permitted by statutory regulation or exceeds the permitted use, you will need to obtain permission directly from the copyright holder. To view a copy of this licence, visit http://creativecommons.org/licenses/by/4.0/.

\section{References}

1. Gao, Q., Di, X., Liu, Y., Yan, Z.: Recovery and recrystallization in modified 9Cr1Mo steel weldments after post-weld heat treatment. Int. J. Press. Vessels Pip. 93-94, 1-6 (2012). https://doi.org/10. 1016/j.ijpvp.2012.03.002

2. Rai, S., Jayakumar, T., Babu Rao, C., Bhattacharya, D.K., Raj, B.: Residual stress measurement in ferritic steel tube welds using X-ray diffraction. Sci. Technol. Weld. Join. 3(4), 204-207 (1998). https://doi.org/10.1179/stw.1998.3.4.204

3. Guo, J., Xu, X., Jepson, M.A.E., Thomson, R.C.: Influence of weld thermal cycle and post weld heat treatment on the microstructure of MarBN steel. Int. J. Press. Vessels Pip. 174, 13-24 (2019). https://doi.org/10.1016/j.ijpvp.2019.05.010

4. Nebhnani, M.C., Bhakta, U.C., Gowrisankar, I., Biswas, D.: Failure of a martensitic stainless steel pipe weld in a fossil fuel power plant. Eng. Fail. Anal. 9, 277-286 (2002). https://doi.org/10.1016/ S1350-6307(01)00019-X

5. Rajaei, M., Elahi, S.H., Mashhadgarme, M.: A novel method for quality control of post weld heat treatment process using modal parameters. NDT\&E Int. 111, 102216 (2020). https://doi.org/10. 1016/j.ndteint.2020.102216

6. Chertov, A.M., Maev, R.G., Severin, F.M.: Acoustic microscopy of internal structure of resistance spot welds. IEEE Trans. Ultrason. 54(8), 1521-1529 (2007). https://doi.org/10.1109/TUFFC. 2007.422

7. Harada, D., Sakai, K., Kiwa, T., Tsukada, T.: Analysis of the internal structure of a spot-weld by magnetic measurement, SINCE 2013. In: Proceedings of the Singapore International NDT Conference \& Exhibition 2013, 19-20 July 2013 (2013)

8. Vertesy, G., Tomas, I.: Nondestructive magnetic inspection of spot welding. NDT\&E Int. 98, 95-100 (2018). https://doi.org/10. 1016/j.ndteint.2018.05.001

9. Tsukada, K., Yoshioka, M., Kiwa, T., Hirano, Y.: A magnetic flux leakage method using a magnetoresistive sensor for nondestructive evaluation of spot welds. NDT \& E Int. 44, 101-105 (2011). https://doi.org/10.1016/j.ndteint.2010.09.012

10. Tsukada, K., Miyake, K., Harada, D., Sakai, K., Kiwa, T.: Magnetic nondestructive test for resistance spot welds using magnetic flux penetration end eddy current methods. J. Nondestruct. Eval. 32, 286-293 (2013). https://doi.org/10.1007/s10921-013-0181-0

11. Lord, A.E., Mason, W.P., Thurston, R.N. (eds.): Physical Acoustics, p. 290. Academic Press, New York (1975)

12. Shibata, M., Ono, K.: Magnetomechanical acoustic emission-a new method for non-destructive stress measurement. NDT Int. 14(5), 227-234 (1981). https://doi.org/10.1016/0308-9126(81) 90075-4

13. Piotrowski, L., Augustyniak, B., Chmielewski, M., Labanowski, J., Lech-Grega, M.: Study on the applicability of the measurements of magnetoelastic properties for a nondestructive evaluation of thermally induced microstructure changes in the P91 grade 
steel. NDT\&E Int. 47, 157-162 (2012). https://doi.org/10.1016/j. ndteint.2012.01.007

14. Piotrowski, L., Chmielewski, M., Kowalewski, Z.: On the application of magnetoelastic properties measurements for plastic deformation level evaluation. J. Electr. Eng. 69(6), 502-506 (2018). https://doi.org/10.2478/jee-2018-0086

15. Buttle, D.J., Briggs, G.A.D., Jakubovics, J.P., Little, E.A., Scruby, C.B.: Magnetoacoustic and Barkhausen emission in ferromagnetic materials. Philos. Trans. R. Soc. Lond. A 320, 363-378 (1986)

16. Piotrowski, L., Augustyniak, B., Chmielewski, M.: On the possibility of the application of magnetoacoustic emission intensity measurements for the diagnosis of thick-walled objects in the industrial environment. Meas. Sci. Technol. 21, 035702 (2010). https://doi.org/10.1088/0957-0233/21/3/035702

17. Pešička, J., Kužel, R., Dronhofer, A., Eggeler, G.: The evolution of dislocation density during heat treatment and creep of tempered martensite ferritic steels. Acta Mater. 51, 4847-4862 (2003). https://doi.org/10.1016/S1359-6454(03)00324-0

18. Augustyniak, B., Chmielewski, M., Piotrowski, L., Sablik, M.J.: Designing a magnetoacoustic emission measurement configuration for measurement of creep damage in power plant boiler tubes. J. Appl. Phys. 91(10), 8897-8899 (2002). https://doi.org/ $10.1063 / 1.1450851$

19. Maciakowski, P., Augustyniak, B., Chmielewski, M., Piotrowski, L.: Application of mechanical Barkhausen noise in assessment of X20 steel properties after heat treatment. J. Electr. Eng. 63(7s), 102-105 (2012)

20. Nakashima, K., Suzuki, M., Futamura, Y., Tsuchiyama, T., Takaki, S.: Limit of dislocation density and dislocation strengthening in iron. Mater. Sci. Forum 503-504, 627-632 (2006)

21. Sato, S., Wagatsuma, K., Suzuki, S., Kumagai, M., Imafuku, M., Tashiro, H., Kajiwara, K., Shobu, T.: Relationship between dislocations and residual stresses in cold-drawn pearlitic steel analyzed by energy-dispersive X-ray diffraction. Mater. Charact. 83, 152-160 (2013). https://doi.org/10.1016/j.matchar.2013.06.017

22. Perevertov, O.: Describing the effect of tempering on hysteresis curves of 54SiCr6 spring steel by the effective field model. J. Magn. Magn. Mater. 324, 1645-1648 (2012). https://doi.org/10. 1016/j.jmmm.2011.12.029
23. Herzer, G.: The random anisotropy model. In: Idzikowski, B., Švec, P., Miglierini, M. (eds.) Properties and Applications of Nanocrystalline Alloys from Amorphous Precursors NATO Science Series (Series II: Mathematics, Physics and Chemistry). Springer, Dordrecht (2005)

24. Chicazumi, S.: Physics of Ferromagnetism (The International Series of Monographs on Physics). Oxford University Press, Oxford (2009)

25. Monlevade, E.F., de Campos, M.F., Franco, F.A., Capo-Sanchez, J., Goldenstein, H., Padovese, L.R.: Magnetic barkhausen noise in quenched carburized nickel-steels. IEEE Trans. Magn. 48(4), 1465-1468 (2012). https://doi.org/10.1109/TMAG.2011.2173666

26. Speich, G.R., Leslie, W.C.: Tempering of steels. Metall. Trans. 3, 1043-1054 (1972). https://doi.org/10.1007/BF02642436

27. De Freitas, D.A., Machado, I.G., Mazzaferro, J.A.E., Gonzalez, A.R., Mazzaferro, C.C.P.: Welding cooling rate effects on microstructure of an API 51 x100 steel. Int. J. Eng. Technol. 5(2), 51-57 (2016). https://doi.org/10.14419/ijet.v5i2.6113

28. Messler, R.W., Jr.: Principles of Welding. WILEY-VCH Verlag $\mathrm{GmbH} \& \mathrm{Co}$, Weinheim (2004)

29. Buttle, D.J., Little, E.A., Scruby, C.B., Briggs, G.A.D., Jakubovics, J.P.: A study of neutron-irradiation damage in alpha-iron with magnetoacoustic and Barkhausen emission. P. R. Soc. A-Math. Phys. 414(1846), 221-236 (1987). https://doi.org/10. 1098/rspa.1987.0141

30. Xu, Y.H., Ma, L., Du, F.M., Ma, X.Y., Ng, D.H.L.: Magnetoacoustic emission and Barkhausen noise of cobalt nickel oriented silicon steel and permalloy. J. Magn. Magn. Mater. 219(2), 166-172 (2000). https://doi.org/10.1016/S0304-8853(00)00416-9

31. Piotrowski, L., Augustyniak, B., Chmielewski, M., Tomas, I.: The influence of plastic deformation on the magnetoelastic properties of the CSN12021 grade steel. J. Magn. Magn. Mater. 321(15), 2331-2335 (2009). https://doi.org/10.1016/j.jmmm.2009.02.028

Publisher's note Springer Nature remains neutral with regard to jurisdictional claims in published maps and institutional affiliations. 